\title{
O problema da linha de cor e a diferença cultural: raça, etnicidade e diáspora no século XXI.
}

\section{The problem of color line and the cultural difference: race, ethnicity and diaspora in the 21 st century.}

Resenha do livro: HALL, Stuart. The Fateful Triangle: Race, Ethnicity and Nation. Cambridge, Massachusetts, London: Harvard University Press, 2017.

$$
\text { Hasani Elioterio dos Santos }{ }^{1}
$$

Recebido em 17/02/2021, aceito em 05/01/2022

Em The Fateful Triangle (2017) Stuart Hall discute assuntos centrais sobre a formação da modernidade e contemporaneidade. Boa parte da estratégia de argumentação de Hall no livro se dá à luz de importantes categorias de análise frequentes nos enredos políticos da história da modernidade como "raça", "etnicidade" e "nacionalidade", tendo em vista suas correlações com a produção discursiva da noção de diferença. The Fateful Triangle faz parte de uma série de publicações da Universidade de Harvard baseadas em palestras (lectures) conferidas por especialistas de diversas áreas do conhecimento sobre temas explorados e tangenciados pelo sociólogo W.E.B. Du Bois - as W.E.B Du Bois Lectures organizada pelo professor Henry Louis Gates Jr.

No prefácio Henry Louis Gates Jr argumenta que a ideia de raça como uma categoria que indica diferença biológica é tão antiga quanto o encontro europeu com as outras civilizações no século XVI. Para ele, a noção de fusão entre diferença fenotípica e cultural constantemente se justapõe com o desejo econômico e a exploração colonial, produzindo o imaginário simbólico do africano como um significante negativo. Deste modo, a categoria raça em vários casos pode ser vista como um amálgama de etnicidade, religião e nacionalidade, ou de uma maneira que venha cada um destes componentes separadamente.

Dentro desse panorama o que intriga o professor Henry Louis Gates Jr na obra de Stuart Hall é a forma que grupos que passam pela experiência da opressão e subalternização atuam em direção à autorrealização e libertação, invertendo essas categorias sem descartá-las de vez, ao

\footnotetext{
${ }^{1}$ Doutorando do Programa de Pós Graduação em Sociologia da Universidade Federal de São Carlos (PPGS/UFSCar), bolsista CAPES. E-mail: hasanisantos@gmail.com; (11) 995016991. Rod. Washington Luiz, s/n Monjolinho, São Carlos - SP, 13565-905
} 
invés de encampar um suposto orgulho racial ou étnico com efeitos de essencialização e fixidez. Para Hall, nós vivemos em um mundo de misturas e migrações, e neste contexto as fronteiras das noções de raça, etnicidade e nacionalidade são fundamentais para entender os significantes de diferença cultural.

A noção de diferença em Stuart Hall é baseada na difference do pós-estruturalismo de Derrida. Ela não diz respeito tão somente a uma diferença pura e simplesmente operacionalizada por uma oposição entre unidades espelhadas, mas sim em termos de uma articulação, ou diferença que defere. Neste sentido, ao trabalharmos com a obra de Hall, temos sempre em vista as formas criativas que grupos e indivíduos marginalizados criam identificações e posicionalidades em uma determinada conjuntura histórica criando uma experiência histórica compartilhada contextual.

Em outras palavras, significa dizer que um dos objetivos de Hall neste brilhante livro é de complicar e perturbar nossas noções, ainda tão persistentes em nossa gramática de convívio social, de raça, etnicidade e nação - a qual ele chama de fateful triangle. A partir desse objetivo crítico ele propõe para os(as) leitores(as) um campo de novas possibilidades para pensarmos nossas noções de pertencimento e os momentos históricos que caracterizam os processos de identificação .

Henry Louis Gates Jr também discorre sobre alguns problemas referentes às interpretações equivocadas da obra de Hall, mencionando que muitas vezes seus escritos sobre raça e cultura são pensados como discursos paralelos, quando na realidade são inextricáveis e conectados, partes componentes de um mesmo pensamento crítico sobre o mundo em que vivemos. Para desmistificar as interpretações que ele julga problemáticas, Henry Louis Gates Jr enumera brevemente algumas das iniciativas e ações que Stuart Hall esteve presente como teórico e organizador.

Durante o fim dos anos 80 Hall esteve à frente da Association of Black Photographers (ABP), ou simplesmente $\underline{\text { Autograph}}$. Nos anos 90 Hall organizou o Institute of International Visual Arts (Iniva). Ambas as organizações têm grande impacto na produção de conteúdo artístico e visual de caráter crítico no Reino Unido e tocam em temas como os impactos da globalização e a migração. A produção teórica de Stuart Hall influenciou importantes artistas 
como Isaac Julien e John Akomfrah e curadores de arte como David A. Bailey, Mark Sealy e Renée Mussai. Além deste movimento artístico negro no interior do Reino Unido, Hall influenciou posteriores produções teóricas de intelectuais contemporâneos renomados como Hazel V. Carby, Kobena Mercer e Paul Gilroy.

Enquanto leitor eu me detive profundamente nestas informações presentes no rico prefácio do livro. Essa passagem me provocou e levou a uma reflexão que julgo pertinente de ser feita nesta resenha, digo particularmente sobre a semelhança entre W.E.B. Du Bois e Stuart Hall. Essa semelhança foi apontada outrora por Les Back e Maggie Tate (2018) em um artigo em que os autores dizem que Stuart Hall é tido como o "Du Bois da Grã-Bretanha"2. Dialogando com eles vejo que um ponto relacional entre Du Bois e Hall, que é justamente a capacidade dos dois de serem intelectuais públicos, organizarem e articularem a produção de conhecimento científico com movimentos artísticos pontuais e específicos que demarcam historicamente a ação da cultura política negra da diáspora de forma criativa.

No caso de Du Bois há uma relação de parte de sua produção teórica e suas proposições e objetivos políticos de conceber a arte como um campo estratégico de produção discursiva em uma perspectiva modernista. Em dois textos, em particular, The Souls of Black Folk (1903) e The Negro Minds Reach Out (1924) ele dá devida atenção para a importância da produção cultural negra e sua capacidade de forjar e criar comunidade por meio de um comprometimento existencial com a "dupla consciência"”.

Du Bois foi responsável direto na fomentação do fértil movimento artístico que se deu na década de 1920 nos EUA, chamado Harlem Renaissance, um intenso e rico movimento artístico que contou com inúmeros participantes como Malvin Gray Johnson, Aaron Douglas, Louis Mailou Jones, Elizabeth Catlett, dentre outros e outras. Tanto Du Bois, como o filósofo Alain Locke e a antropóloga Zora Neale Hurston foram alguns dos teóricos responsáveis por essa "bomba cultural" negra que explodiu em pleno Harlem no período posterior a I Guerra Mundial.

\footnotetext{
${ }^{2} \mathrm{Na}$ realidade essa afirmação foi feita pelo professor Henry Louis Gates Jr., nos dias após a morte de Stuart Hall em 10 de fevereiro de 2014. Les Back e Maggie Tate (2018) relembram dessa afirmação e estruturam o argumento do artigo em torno dessa ideia.

3 A ideia de "dupla consciência" em Du Bois refere-se a difícil e conflituosa convivência entre o pertencimento branco e o não-branco, uma vez que o processo de formação subjetiva racializada se dá tendo o polo branco como eixo orientador o negro se vê como tal em função da perspectiva e forma de olhar branca. Trata-se de uma noção que retrata a luta em torno do pertencimento travada no interior do corpo negro.
} 
Essa informação - sobre a importância de Du Bois para o Harlem Renaissance e de Stuart Hall para a produção fotográfica e cinematográfica de migrantes caribenhos, africanos e asiáticos no Reino Unido (ABP e Iniva) - é um tema que de fato me chama atenção e corrobora ainda mais com os argumentos apresentados por Les Back e Maggie Tate (2018). Isso significa que a existência de diálogos e consonância entre as práticas e produções de Du Bois e Stuart Hall é identificável, principalmente a respeito de como os dois concebiam os movimentos artísticos que ambos faziam parte, integravam e organizavam.

Essas informações nos possibilitam ver que a produção cultural, e a cultura - seu campo maior de disputa e luta por hegemonia - é um elemento central das formulações e proposições dos dois autores. Ambos representam o pensamento e o sistema de circulação de ideias da intelectualidade negra em escala transnacional. E personificam em suas trajetórias a quebra de paradigma discutida por Gilroy (1993) em Black Atlantic sobre como cultura e política, assim como estética e ética não estão deslocados, ou separados no interior do pensamento e da produção cultural e teórica do Atlântico Negro.

Isso reflete no modelo de coexistência entre poiésis e poética nessa estrutura rizomática, identificada por Paul Gilroy como Atlântico Negro - que é um modelo de possibilidade interpretativa sobre as produções culturais e a teoria social negra em conjunto - que desrespeita as noções da modernidade iluminista de divisão entre o cultural e o político. Para boa parte dos pensadores do Atlântico Negro, agir culturalmente é interferir politicamente de forma simultânea. Du Bois e Stuart Hall representam de maneira admirável essa premissa.

As reflexões de Stuart Hall estão de fato orientadas a uma forma de se pensar relacionalmente e contextualmente. Para Hall tanto a cultura como a política são práticas sem garantias, e isso é estendido para suas noções de raça, etnicidade e nacionalidade. Por mais que sejam ideias que aparentam ser permanentes, perseverantes e imutáveis em termos de convívio social, elas se alteram, transformam e se modificam ao longo dos eixos tempo e espaço.

Em Fateful Triangle há certamente uma discussão sobre estas categorias que se interligam e entrecruzam nos processos sociais da vida real e cotidiana. Stuart Hall ao fazer uma análise crítica sobre a produção de diferença cultural nos mostra que estas categorias são três formas de representar discursivamente a noção de diferença e produzir historicamente relações de poder ao longo do período que classificamos como modernidade. Hall aponta para a agência da noção de diferença na operacionalização discursiva e política da realidade social. 
Nestes termos Hall atualiza o conhecido diagnóstico sociológico de Du Bois sobre o problema do século XX - o problema da linha de cor $(\underline{\text { color line }})^{4}$ - que para Hall é visto pela ótica do século XXI e o problema de se conviver com a diferença. Essa atualização do pensamento duboisiano não é somente um apontamento análogo sobre o problema da color line apresentado por $\mathrm{Du}$ Bois no início do século $\mathrm{XX}$, é, sobretudo, uma transformação historicamente específica e contextual dessa formulação nos termos de diferença cultural.

O primeiro capítulo do livro se chama "Raça - significante deslizante" e disserta sobre as formas que a categoria raça, em sua perspectiva biológica, se mostra aparentemente como uma ideia perene no tempo e no espaço, apesar de toda uma série de esforços feitos para mostrar que seu caráter não é biológico, mas sim sociológico e histórico. A raça é uma categoria que não tem nenhuma validade científica que respalde sua relevância na biologia, porém diante da força das produções discursivas sobre a diferença revelam-se toda uma disputa em torno dos recursos simbólicos da categoria raça e sua possibilidade de dar sentido às condições da vida social de grupos e indivíduos.

Daí sua importância como categoria sócio-histórica e não biológica, tendo em vista uma série de comprovações científicas que desmentem a perspectiva biológica do termo ${ }^{5}$. Raça, nesse sentido, é uma construção sócio-histórica e sua característica é o fato de ser um significante deslizante que adquire, em determinados contextos e situações históricas, características e configurações específicas. Tais características, nós enquanto analistas podemos capturar dando visibilidade às políticas discursivas que giram em torno desse significante e as cadeias de equivalências produzidas pela articulação de semelhanças e diferenças.

O segundo capítulo "Etnicidade e Diferença em tempos globais" inicia com um debate sobre os discursos fechados da etnicidade e seus rumos para um caminho que leva para o "tudo ou nada" essencialista, este que versa a respeito de uma etnicidade natural imutável, assim como a perspectiva biologizante (sem validade científica) sobre o termo raça. Deste modo, Hall faz uma leitura crítica anti-essencialista da ideia de raça e etnicidade. Um dos eixos de análise que estão presentes no livro é a atenção que Hall dá para os problemas que concernem aos discursos

\footnotetext{
${ }^{4}$ Linha de Cor, ou Color Line é pensada por Du Bois como uma estrutura global que configura estratificações e hierarquizações sociais por meio dos usos políticos da categoria "raça". As "raças", portanto, são categorias sociológicas e políticas e não biológicas que foram úteis à formação dos impérios ocidentais e da manutenção do colonialismo. A Linha de Cor é entendida como uma estrutura global de opressão e estratificação social.

${ }^{5}$ Como a descoberta do DNA em 1953, ou o caso de Henrietta Lacks dois anos antes, em 1951, por exemplo.
} 
fechados sobre raça, etnicidade e nação e sua produção de uma closura (fechamento) de um grupo, o que acaba limitando nossa perspectiva histórica a respeito destes termos.

Neste capítulo Hall fala do solo contraditório - sobre qual o impacto da globalização, a migração e a desigual multiculturalização da vida cotidiana está emergindo - como um terreno contemporâneo do conflito cultural. Trata-se do retorno da etnicidade como um significante deslizante e ambivalente nas políticas culturais da diferença que caracteriza nosso momento global. Os efeitos desse retorno das etnicidades são o deslocamento do universalismo do iluminismo e a subsequente re-valorização da diferença entre os movimentos sociais.

Hall se propõe a deslocar o conceito de etnicidade (para além de seu deslocamento de um pólo negativo para o positivo, e a reavaliação dos significantes de diferença) para desconstruir o que ele alega ser a sua sedução desarmante. Para ele a etnicidade é como a face de Jano - duas caras - contraditória e que desliza características da cultura na natureza e vice-versa ${ }^{6}$. A questão para Hall é que estamos sempre negociando posicionalidades.

Isso nos leva a pensar que a identidade cultural é sempre específica, fundamentada através da indicação/marcação de similaridade e diferença. A identificação é um processo de marcação discursiva que dá a cada identidade cultural suas histórias e linguagens. Essas condições de identificação têm sempre efeitos reais, materiais e simbólicos. As identidades culturais são pontos de identificação ou sutura, feitas dentro dos discursos da história e cultura para posicionar o sujeito em relação às suas noções de passado (que é sempre uma questão discursiva). Portanto, para ele as identidades culturais importam, não porque nos fixa em um lugar politicamente, mas porque elas estão sempre em jogo e negociação. São elas que nós temos a ganhar e perder em termos de políticas culturais.

A partir desta perspectiva crítica Hall elabora uma proposição dando visibilidade às "novas etnicidades". Esta proposta é representada e reproduzida em algumas manifestações artísticas que não estão preocupadas em eternizar uma identidade em mitos de pureza e origem e que não se desdobram em formas exclusionárias e fechadas de lidar com a diferença. A aposta de Hall é nas modalidades de identificação coletiva sujeitas a condições históricas que passam diante de nossos olhos e percorrem nossas vidas, trata-se de um posicionamento contextual e estratégico.

\footnotetext{
${ }^{6} \mathrm{Na}$ mitologia Romana Jano (ou Janus em Latim) é uma deidade das mudanças, ele é representado por um homem com duas faces olhando para direções opostas, frente e verso.
} 
Essa sua perspectiva é um ponto de diálogo que nos liga com o terceiro capítulo do livro "Nações e Diáspora". O ponto de partida do autor neste capítulo são as formações da diáspora a qual a história do Caribe está fundamentada, conjuntamente com os elementos ameríndios (ou americanos), europeus e africanos. Esses elementos são pensados por Hall como "presenças culturais" que se manifestam nas relações sociais das ilhas que constituem a região do Caribe. Todas essas presenças são rearticuladas em novas configurações que representam o paradigma expresso pelo termo diáspora.

A diáspora não é uma perda trágica de uma origem, raiz (ㅁoots). Ela é uma rede polissêmica e dissonante de entrecruzamentos culturais (ㅁoutes). São essas rotas de entrecruzamentos culturais que dão o caráter dinâmico e inovador de um período marcado por diálogos transnacionais, seja em termos culturais, políticos ou econômicos, que para Hall operam como esferas da vida social que são trabalhadas e articuladas conjuntamente.

A questão da nação é um ponto importante de análise do autor, pois para ele as nações não emergem pura e simplesmente, elas são forjadas e formadas. Nação é uma comunidade simbólica, suas dimensões têm em vista a produção de poder que gera identidade e aliança. E dentro da gramática de convívio social no Estado-Nação todo discurso sobre identidade é feito pela e através da diferença e sua articulação com o "eu" e o "outro". As identidades nacionais da modernidade articulam política e cultura - duas metades da equação nacional para Hall.

A sociologia de Stuart Hall é marcada por essa perspectiva de ver a sociedade e suas instâncias constitutivas de um modo que estejam sempre abertas para as contingências históricas. Tais contingências são sensíveis aos processos culturais, nesse sentido é relevante atribuir a Hall a característica de conferir à cultura uma importância para lidar com processos históricos e sociais marcados por disputas políticas. Para o Centro de Estudos Culturais Contemporâneos de Birmingham $^{7}$ a cultura é um elemento chave para entender as mudanças sociais que passamos. É na instância cultural que enquanto analistas dos processos sociais podemos ver as disputas de forças emergentes na tentativa de fazerem valer suas presenças em termos de hegemonia.

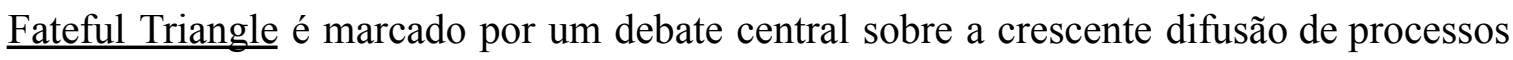
de antagonização em termos de diferença cultural. Para Hall este é um dos desafios de nossos

\footnotetext{
${ }^{7}$ Centro de Estudos Culturais Contemporâneos, na Universidade de Birmingham, é o grupo que Stuart Hall esteve filiado desde 1964, quando este recebeu o convite de Richard Hoggart para participar. Mais tarde Hall tornou-se diretor deste centro de estudos e pesquisas.
} 
tempos. É por esse motivo que vemos que a noção de contradição em nosso presente momento está articulada com lutas em torno das diferenças e dos processos de identificação, ou seja, em termos de experiência de pertencimento coletivo - codificado no livro em termos de raça, etnicidade e nação - que compõe grande parte deste nosso panorama de disputas e conflitos políticos.

Um exemplo claro citado por Kobena Mercer (2017, p. 21) na introdução do livro é a atenção que Hall dá à proliferação de identidades hifenizadas como, franco-argelinos(as); turco-germânicos(as); afro-americanos(as); latino-americanos(as); afro-brasileiros(as); afro-canadenses; inclusive os afro-caribenhos(as), cuja tradição intelectual é pensada pelo próprio Stuart Hall e por Borda (2018), através da ideia de "prisma de formação caribenha".

Esse prisma de formação de pensamento é a metáfora do deslocamento feito por autores(as) afro-caribenhos(as), como por exemplo, Oliver Cox, C.L.R. James, George Padmore, Sylvia Wynter, Frantz Fanon, dentre outros(as). Assim como a ideia do prisma que desloca e articula feixes de luz, a noção dos deslocamentos e trajetórias destes autores representa a fuga, ou deslocamento de perspectivas teóricas e culturais. Essa tradição de pensamento intelectual afro-caribenha pode ser vista como uma expressão particular de uma problemática global e mais ampla (BORDA, 2018, p. 57).

O prisma de formação de pensamento afro-caribenho adquire a característica de uma "consciência oposicional" que é produto direto da experiência de circulação e trajetória desses(as) autores(as) e suas experiências com diferentes gramáticas do processo de racialização nos grandes centros metropolitanos e imperiais. Para Borda (2018) a tradição de pensamento afro-caribenha, lida na chave do prisma, oferece uma possibilidade, uma janela de fuga da zona do não-ser (na perspectiva fanoniana), ou uma fuga do nível abaixo da linha de cor (em termos duboisianos).

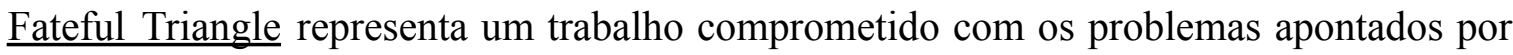
uma tradição de pensamento, está presente em Du Bois e em Fanon, e os articula à luz de alguns eventos do fim do século XX e início do século XXI na chave da diferença cultural. A globalização é um fato que perpassa todo o livro. Para Hall o processo de globalização fraturou as coordenadas temporais e espaciais de nossos sistemas de representação para as noções de identidade cultural e comunidade imaginada (pertencimento). 
Atualmente no século XXI vivemos um momento em que o fluxo cultural e os laços coletivos estão operando acima e abaixo do nível do Estado-Nação, funcionando como escalas interpenetrantes que causam uma disrupção nas distinções convencionais de vizinhança e região. Um dos objetos de pesquisa de Hall neste trabalho é visibilizar este aspecto impressionante das novas formas de globalização, ao lado das tendências de homogeneização há também a proliferação da diferença em todas as suas formas.

A globalização no século XXI é um processo desigual, com efeitos dramáticos e diferentes em diversos locais. O fato é que desde a colonização tempos e espaços diferentes nunca coexistiram pacificamente, mas foram na realidade truncados e condensados dentro de um cronótopo dominante, abstrato e imperial que é o tempo ocidental. A ideia de que as periferias coloniais são espaços fechados, etnicamente puras, culturalmente tradicionais e eternamente imperturbáveis é meramente uma fantasia sobre o outro. Nesse sentido, um dos perigos da globalização é sua disseminação das narrativas homogeneizantes.

Encaminhando esta resenha para o fim, há uma passagem que considero interessante sobre os efeitos da globalização. Refiro-me ao que Hall chama de "crise de identidade", identificada por ele nos anos 50-60 na Grã Bretanha, e que advém das grandes migrações e a mudança da geopolítica imperial em torno dos EUA como o novo império insurgente após a II Guerra Mundial. As migrações em massa, por exemplo, deslizam essa equação simplificada de que um povo equivale a um etnos sob o mesmo "teto homogêneo". Para Hall há uma característica de contradição na migração - ela proporcionou o desenho do que concebemos como modernidade e desafia a própria modernidade (suas fronteiras de Estado-Nação). O recuo da antiga noção de Estado-Nação é uma grande questão presente no fim do século XX.

No entanto há sua contraofensiva - a restauração conservadora de um absolutismo étnico para pavimentar novas histórias de identidade cultural. O Fundamentalismo (seja em sua perspectiva ocidental ou não ocidental), por exemplo, é uma resposta conservadora às diferenças e seu avanço contraditório na globalização. O Fundamentalismo para Hall representa a reação aos avanços da hibridização da diferença e seus avanços contraditórios, de maneira unitária, homogeneizante e essencialista.

O livro se encerra com uma discussão sobre a diáspora e a estrutura rizomática e fractal que representa o Atlântico Negro. Para Hall a agência criativa negra no novo mundo se deu a 
partir do desenho de uma ideia alternativa de nação política, lida na chave do transnacionalismo negro. Para ele, o termo diáspora está em contraposição ao termo nação e propõe um modelo novo e inovador de abertura da política cultural. Como essa proposição está em aberto, é importante dizer que a noção de diáspora também está sob rasura.

Diáspora para Hall é a metáfora para uma produção discursiva de um novo interstício espacial (terceiro espaço, entre-lugar/tempo) que advém de um longo processo de globalização, cujos elementos chave são os movimentos físicos e culturais de desterritorialização e migração. Esses elementos são chaves para a compreensão de nosso momento atual e os sintomas das consequências de uma conexão global, assim como de sua disjunção. O desafio é compreender como a diáspora pode ser vista por suas similaridades e diferenças e como elas se repetem simultaneamente e estão deslocadas uma da outra.

Hall é um autor que pensa a diáspora em direção ao futuro, não seria correto dizer que sua proposição a respeito do termo sugere um retorno às raízes, ou às tradições culturais. A diáspora não é uma estrutura unitária, se trata da rearticulação de experiências e de pensar a diáspora como um significante de tradução das diferenças, ou seja, pensar em termos de rotas que nos levem a considerar não quem nós somos ou de onde viemos, mas sim quem nós podemos nos tornar e para onde podemos ir.

\section{Referências}

BACK, Les; TATE, Maggie. 'For a Sociological Reconstruction: W.E.B. Du Bois, Stuart Hall and Segregated Sociology'. In: Sociological Research Online. 2018.

BORDA, Erik Wellington Barbosa. Prisma de formação caribenha: a produção social de uma consciência oposicional em C. L. R. James e Oliver C. Cox. PPGS - UFSCar, São Carlos, 2018. Disponível em: https://repositorio.ufscar.br/handle/ufscar/9895?show=full

GILROY, Paul. The Black Atlantic: Modernity and Double Consciousness. Cambridge, Mass. :Harvard University Press, 1993. 